\title{
Quaternized rice husk as sorbent for reactive dyes
}

\begin{abstract}
A study on the sorption of hydrolyzed Reactive Blue 2 by quaternized rice husk showed that the binding capacity of the sorbent was not suppressed by dyebath conditions of high concentration of electrolytes. Its sorption capacity decreased with increasing concentration of $\mathrm{NaOH}$. Complete regeneration of dye-coated quaternized rice husk was not possible under base treatment, suggesting chemisorption of dye molecules on the sorbent material. The physical stability of the quaternized rice husk was examined by treating it with various concentrations of $\mathrm{NaOH}$ solution. Results showed that no dissolution of sorbent occurred, even in $1 \mathrm{M} \mathrm{NaOH}$ solution.
\end{abstract}

Keyword: Quaternized rice husk; Sorption; Reactive dyes 